Tropical Journal of Pharmaceutical Research December 2014; 13 (12): 2101-2108

ISSN: $1596-5996$ (print); 1596-9827 (electronic)

(C) Pharmacotherapy Group, Faculty of Pharmacy, University of Benin, Benin City, 300001 Nigeria.

All rights reserved.

Available online at http://www.tjpr.org

Original Research Article

http://dx.doi.org/10.4314/tjpr.v13i12.22

\title{
Osteoporosis Amongst Jordanians: Effect of Pharmacist- Directed Brochure Education on People's Knowledge
}

\author{
Eman Elayeh, Amal Akour ${ }^{1}$, Al-Motassem Yousef ${ }^{1}$, Doa'a Farah ${ }^{2}$, Majd hamaly ${ }^{1}$ \\ and Iman Basheti ${ }^{3}$ \\ ${ }^{1}$ Department of Biopharmaceutics and Clinical Pharmacy, Faculty of Pharmacy, University of Jordan, Amman, ${ }^{2}$ Department of \\ Biopharmaceutics and Clinical Pharmacy, Faculty of Pharmacy, Zarqa Private University, Zarqa, ${ }^{3}$ Department of \\ Biopharmaceutics and Clinical Pharmacy, Faculty of Pharmacy, Applied Science University, Amman, Jordan
}

*For correspondence: Email: dr_iman@asu.edu.jo

Received: 23 July 2014

Revised accepted: 10 November 2014

\begin{abstract}
Purpose: To assess osteoporosis knowledge among Jordanian people and to evaluate the effect of a pharmacist-directed brochure on the knowledge.

Methods: This study was an interventional study conducted in two major cities of Jordan. The baseline knowledge of participants about osteoporosis (KOS) was evaluated by a validated, back-translated questionnaire. Thereafter, participants received a pharmacist-directed brochure education about osteoporosis, and then their knowledge was assessed using the same questionnaire.

Results: Of the 395 people visiting community pharmacies in Jordan that were enrolled into the study, their age ranged from 18 to $>60$ years old and $70.4 \%$ were female. More than $60 \%$ of the participants had good baseline knowledge about osteoporosis (median KOS > $50 \%$ ). Gender, education and smoking status significantly affected baseline knowledge. The pharmacist-directed brochure significantly improved KOS score (78 \% vs. $56 \%, p<0.001)$.

Conclusion: Current knowledge of Jordanians about osteoporosis is moderate, especially females. However, majority of Jordanians believe that they need more education about osteoporosis. The educational brochure significantly improved knowledge in various important aspects. Comprehensive educational programs, which cover more areas of osteoporosis knowledge, and that should not necessarily depend only on written material, is therefore recommended.
\end{abstract}

Keywords: Osteoporosis, Patient education, Pharmacists, Disease management

Tropical Journal of Pharmaceutical Research is indexed by Science Citation Index (SciSearch), Scopus, International Pharmaceutical Abstract, Chemical Abstracts, Embase, Index Copernicus, EBSCO, African Index Medicus, JournalSeek, Journal Citation Reports/Science Edition, Directory of Open Access Journals (DOAJ), African Journal Online, Bioline International, Open-J-Gate and Pharmacy Abstracts

\section{INTRODUCTION}

Osteoporosis is a major public health problem and the most common skeletal disorder. It has been described as a silent epidemic affecting millions worldwide. It is silent in the respect that it is usually asymptomatic until a complication such as a fracture occurs [1]. The World Health Organization (WHO) has defined osteoporosis as 'low bone mass and micro-architectural deterioration of bone tissue leading to enhanced bone fragility and consequent increase in fracture' [1]. Low bone mineral density has been found to be related to most fractures even traumatic fractures, increasing the public health impact of osteoporosis [2].

Osteoporosis is one of the major quality of life threatening diseases for women, regardless of race or ethnicity. Seventy one percent of fractures have been found to occur in women, accounting for $75 \%$ of all fracture-related costs. 
White women account for the majority of all fractures (89\%), followed by blacks (4\%), Hispanics (4\%), and other women (3\%) [3].

Osteoporosis related fractures lead to a substantial burden of disability, costs, and mortality. It has been recognized that one of the major consequences following hip fractures is mortality. Mortality due to osteoporosis was found to be greater in men at any age, but after the age of 80 , the gender difference was reported to decrease [3]. The reported prevalence of osteoporosis in Jordan ranges from $13 \%$ to $44 \%[4,5]$. With such a high prevalence, studies exploring osteoporosis risk factors and disease knowledge are needed.

Globally, public awareness of osteoporosis continues to be low, especially in developing countries [6]. Patient education is very important in osteoporosis, and many studies have been conducted to improve knowledge of patients, using workshops and group discussions. Health education programs involving osteoporosis have been shown to be effective in improving knowledge and awareness among patients [6,7], and in keeping their knowledge over time $[7,8]$. However, no previous study has explored the effect of education on Arabic speaking men and women.

The aim of this study is to assess osteoporosis knowledge among Jordanian population, specifically females, and to evaluate the effect of a pharmacist-assisted educational intervention on their disease knowledge.

\section{EXPERIMENTAL}

\section{Study design}

This is a single blinded, monophasic interventional study which was run for three months, from June to august 2013. Participants were randomly recruited from Amman and Zarqa, the largest two cities in Jordan. Ethics approval for the study was obtained from the University of Jordan Ethics committee. Trained pharmacy students were assigned to conduct the interview and to distribute the questionnaire to subjects from different predetermined areas. Inclusion criteria included pharmacy client above the age of 18, who could speak Arabic and has resided in Jordan for at least 12 months, with no mental disabilities.

For those who accepted to be included in the study, written informed consent forms were signed. Participants were then asked to fill a validated self-administered questionnaire, to determine their knowledge about osteoporosis.

All participants were then delivered an Educational intervention, using a pharmacistdirected brochure about osteoporosis. This educational intervention was designed to take about 10 minutes.

Participants were thereafter asked to complete the questionnaires again. Students took back the completed questionnaire to the researchers for data entry and analysis. The time allocated for participants to complete the questionnaire (pre and post intervention) was $20 \mathrm{~min}$.

\section{Questionnaire validation}

The questionnaire was derived from previously validated published studies $[9,10]$. Questions were translated into lay Arabic language, and then validated for content and clarity of language by distributing it to 20 subjects, followed by the elimination or modification of unnecessary or ambiguous questions.

The final form of the questionnaire consisted of 2 main areas: 1) subjects' socio-demographics, 2) Knowledge about osteoporosis and its risk factors which consisted of 16 questions written in a 5-point Likert- scale type, and 2 multiple choice questions, which were also included in the calculation of knowledge of osteoporosis score (KOS). Hence the KOS was based on 18 questions. The score was then changed to a percentage for each participant.

Subjects were asked to refill only the second item of the questionnaire that is related to osteoporosis knowledge and its risk factors after reading the pharmacist- directed brochure.

A survey coordinator was selected to manage the logistic aspects of the survey, train students to administer the survey, monitor data collections and track responses. A selected group of 5 th and 6 th year pharmacy students of University of Jordan were trained to administer the questionnaire to a vast majority of heterogeneous population. During the participants interview, students did not identify themselves as health care professionals, but as independent researchers, to decrease social biases.

\section{Statistical analysis}

Descriptive statistics were used to describe demographic and disease characteristics of participants. Percentages and frequencies were 
used for the categorical variables, while median and Inter-quartile range was calculated for continuous variables. Non-parametric statistical tests were used accordingly. Mann-Whitney test, Kruskal-Wallis test and Wilcoxon signed-rank test were used to test the differences in KOS at different levels (baseline and after reading the pharmacist- directed brochure) between groups. Differences in the percentage of correct answers for each question before and after reading the pharmacist- directed brochure were assessed using McNemar test. Spearman correlation coefficient was used to identify relationships between baseline knowledge score and gain in knowledge after reading the pharmacist- directed brochure.

Backward stepwise linear regression was conducted to identify factors with significant association predicting gain in knowledge after reading the pharmacist- directed brochure.

All statistical analyses were performed using SPSS version 16.0 (SPSS Inc., Chicago, IL). The significance level was set at $p$ less than 0.01 to compensate for multiple comparisons (Bonferroni correction).

Sample size calculation was based on the population of Amman $(1,206,266)$ in the year 2010 [11]. A minimum sample size of 385 was calculated, for a margin error of $5 \%$, confidence level of $95 \%$, and a response distribution of 50 $\%$.

\section{RESULTS}

Of the 400 men and women who agreed to participate in the study, 395 completed the entire questionnaire. Five participants were excluded from analysis because their gender was not reported in the questionnaire.

Socio-demographic characteristics for participants are presented in Table 1. Seventy percent of participants were females. The majority of participants had a bachelors degree $(56.7 \%)$ and a majority $(47.2 \%)$ was in the age range of 18-29 years. Participants were either single $(44.9 \%)$ or married $(49.7 \%)$ with more than $60 \%$ of them were not working. Less than $50 \%$ of participants were either obese (13.9\%) or overweight $(32.7 \%)$, and $79.9 \%$ denied smoking.

The risk factors for osteoporosis that were identified in this study are summarized in Table 2.
Seven percent $(n=25)$ of participants had an established diagnosis of osteoporosis. The fifth of the participants had a family history of osteoporosis ( $n=75), 70 \%$ of participants had a positive family history of osteoporosis from the maternal side $(n=35)$.

\section{Osteoporosis knowledge before education}

The median score for the Knowledge of Osteoporosis Score (KOS) before education was $56 \%$. Only $29.5 \%$ (117) of the participants believed that they have sufficient knowledge about osteoporosis. Results showed that $68.6 \%$ (271) of participants had sufficient knowledge about osteoporosis (KOS > 50).

More than $70 \%$ of participants were able to recognize that osteoporosis is directly responsible for disabling hip fracture however $77.9 \%$ failed to recognize death as a potential outcome of the disease.

Participants were aware of many risk factors for osteoporosis, such as aging (88.5 \%, n = 347), smoking $(61.1 \%, \mathrm{n}=238)$, lack of exposure to sun $(73.9 \%, n=286)$, heredity $(59.0 \%, n=235)$, lack of exercise $(76.8 \%, n=300)$ and menopause $(63.6 \%, n=247)$.

A calcium rich diet was considered to have a protective effect from osteoporosis by $87.3 \%$ (n $=342$ ) of the participants. However, only $32.7 \%$ of participants were able to identify calcium rich foods among the choices. The less well-known risk factors by participants were drinking coffee (36.8\%, $n=145)$.

Seventy seven percent $(n=302)$ of participants reported never having discussed osteoporosis with their physician. However, $65.5 \%$ ( $n=249)$ were interested in discussing osteoporosis with their physicians.

As shown in Table 1, there was a significant difference in KOS before reading the pharmacistdirected brochure due to gender, educational level, and smoking status. Females had higher KOS at baseline compared to males (56\% vs. 50 $\%)$. KOS at baseline was higher in non-smokers as compared to smokers (78 vs. 44). Surprisingly, family history of osteoporosis and established diagnosis of osteoporosis were not associated with better knowledge at baseline. 
Table 1: Socio-demographic characteristics of participants $(n=395)$ with differences in knowledge before and after reading the pharmacist-directed brochure

\begin{tabular}{|c|c|c|c|c|c|c|c|}
\hline Variables & n (\%) & $\begin{array}{l}\text { Pre- } \\
\text { knowled } \\
\text { ge } \\
\text { sconre }\end{array}$ & $\underset{*}{P \text {-value }}$ & $\begin{array}{l}\text { Post- } \\
\text { knowledg } \\
\text { e score }\end{array}$ & $P$-value * & $\begin{array}{l}\text { Gain in } \\
\text { knowledg } \\
\text { e score }\end{array}$ & $P$-value * \\
\hline & & $\begin{array}{l}\text { Median } \\
\text { (IQR) }\end{array}$ & & $\begin{array}{l}\text { Median } \\
\text { (IQR) }\end{array}$ & & $\begin{array}{l}\text { Median } \\
\text { (IQR) }\end{array}$ & \\
\hline Age $^{\top}$ & & & 0.84 & & 0.814 & & 0.583 \\
\hline $18-29$ & $\begin{array}{l}182(47.1)) \\
\text { (॥ \ }\end{array}$ & $56(23)$ & & $78(28.5)$ & & $16(23)$ & \\
\hline $30-49$ & $98(25.4)$ & $56(28)$ & & $78(39)$ & & $17(29.25)$ & \\
\hline $50-60$ & $79(20.5)$ & $56(17)$ & & $72(45)$ & & $12(28)$ & \\
\hline$>60$ & $27(7.0)$ & $50(23)$ & & $72(39)$ & & $11(39)$ & \\
\hline Gender ${ }^{\ddagger}$ & & & $<0.0001$ & & $<0.0001$ & & $<0.0001$ \\
\hline Males & $\begin{array}{l}117(29.6) \\
\operatorname{lnn}=1\end{array}$ & $50(23)$ & & $44(17)$ & & $0.00(32.5)$ & \\
\hline Females & $\begin{array}{l}278(70.4) \\
7 \cap 1 \backslash 17 n \text { 1 }\end{array}$ & $56(17)$ & & $83(17)$ & & $22(22)$ & \\
\hline Educational level $^{\top}$ & & & 0.006 & & 0.482 & & 0.062 \\
\hline Primary & $47(12.1)$ & $56(22)$ & & $72(33)$ & & $16(32)$ & \\
\hline Secondary & $43(11.0)$ & $50(23)$ & & $78(39)$ & & $17(32)$ & \\
\hline Some college & $56(14.4)$ & $56(20)$ & & $78(26.5)$ & & $22(28)$ & \\
\hline University & $\begin{array}{l}221(62.5) \\
\text { Iᄃ匹 דI }\end{array}$ & $56(23)$ & & $78(45)$ & & $16(27)$ & \\
\hline Marital status $^{\top}$ & $23(5.9)$ & & 0.535 & & 0.043 & & 0.051 \\
\hline Single & $\begin{array}{l}175(44.9) \\
\text { I^ ภ }\end{array}$ & $56(28)$ & & $78(39)$ & & $16(28)$ & \\
\hline Married & $\begin{array}{l}194(49.7) \\
\ln \backslash 1\end{array}$ & $56(23)$ & & $72(39)$ & & $16(28)$ & \\
\hline Widow & $16(4.1)$ & $56(26.5)$ & & $83(20.75)$ & & $33(48.25)$ & \\
\hline Divorced & $5(1.3)$ & $72(33)$ & & $94(27.5)$ & & $22(10.5)$ & \\
\hline Monthly income ${ }^{\ddagger}$ & & & 0.998 & & 0.757 & & 0.560 \\
\hline > JD 500 & $\begin{array}{l}249(72.8)( \\
=1 \text { ol }\end{array}$ & $56(23)$ & & $78(39)$ & & $16(28)$ & \\
\hline$<J D 500$ & $93(27.2)$ & $56(23)$ & & $78(36)$ & & $16(27.5)$ & \\
\hline Work $^{\dagger}$ & & & 0.791 & & 0.432 & & 0.212 \\
\hline Not working & $\begin{array}{l}222(61.8) \\
\therefore=1 \mathrm{nI}\end{array}$ & $56(23)$ & & $78(28)$ & & $17(28)$ & \\
\hline Working part time & $35(9.7)$ & 56 ( 28) & & $61(44)$ & & $5(33)$ & \\
\hline Working full-time & $\begin{array}{l}102(28.5) \\
\text { 10о } 11\end{array}$ & $56(280$ & & $67(40.5)$ & & $11(28)$ & \\
\hline Smoking status ${ }^{\dagger}$ & & & 0.009 & & $<0.0001$ & & $<0.0001$ \\
\hline Smoker & $50(13.4)$ & $50(23)$ & & $44(45)$ & & $17(28)$ & \\
\hline Non-smoker & $\begin{array}{l}298(79.9) \\
\ln n\end{array}$ & $56(23)$ & & $78(28)$ & & $0.00(41.5)$ & \\
\hline Ex-smoker & $25(6.7)$ & $50(22)$ & & $50(41.5)$ & & $0.000(34)$ & \\
\hline $\mathrm{BMI}^{\dagger}$ & & & 0.430 & & 0.126 & & 0.403 \\
\hline$<25$ & $\begin{array}{l}176(53.3) \\
\text { (ז丂 }\end{array}$ & $56(23)$ & & $78(33)$ & & $17(28)$ & \\
\hline $25-29.9$ & 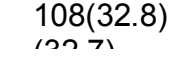 & $56(22)$ & & $72(45)$ & & $16(33)$ & \\
\hline $30-40$ & $46(13.9)$ & $56(18.5)$ & & $78(27)$ & & $16(23)$ & \\
\hline
\end{tabular}

"Significant at $\alpha=0.01$ to compensate for multiple analysis (Bonferroni correction); ${ }^{\dagger}$ Kruskal-Wallis; ${ }^{\ddagger}$ MannWhiteny $U$ test. IQR: inter-quartile range 


\section{Osteoporosis knowledge post-education}

The median score for the KOS after reading the pharmacist- directed brochure was $78 \%$, with significant difference in the KOS before and after reading the pharmacist- directed brochure $(78 \%$ vs. $56 \% ; p<0.001$ ). The post knowledge score was significantly higher in females compared to males $(83 \%$ vs. $44 \%, p<0.0001)$ (Table 3 ).

Results from linear regression analysis (backward method) $\left(R^{2}=0.452, p<0.0001\right)$ showed a significant correlation between gain in knowledge and lower KOS scores before education. Another factor with significant associations was gender $(p<0.0001)$.
Table 2: Osteoporosis risk factors among participants $(\mathrm{N}=395)$

\begin{tabular}{ll}
\hline Variable & N (\%) \\
\hline History of fracture & $86(21.7)$ \\
Family history of osteoporosis & $75(20.6)$ \\
Mother & $35(47.3)$ \\
Grandmother & $13(17.6)$ \\
Sister & $10(13.5)$ \\
Aunts & $8(10.8)$ \\
Family history of hip fracture & $65(16.9)$ \\
Prescribed corticosteroids & $40(10.2)$ \\
Established diagnosis of Rheumatoid & $34(9.0)$ \\
arthritis & $348(88.5)$ \\
No calcium supplement intake & $61(22.5)$ \\
Post-menopausal women & $50(13.4)$ \\
Smoking & $154(46.6)$ \\
BMl > 25 Kg/m² (overweight and & \\
obese) & \\
\hline
\end{tabular}

Table 3: Summary of correct answers before and after education

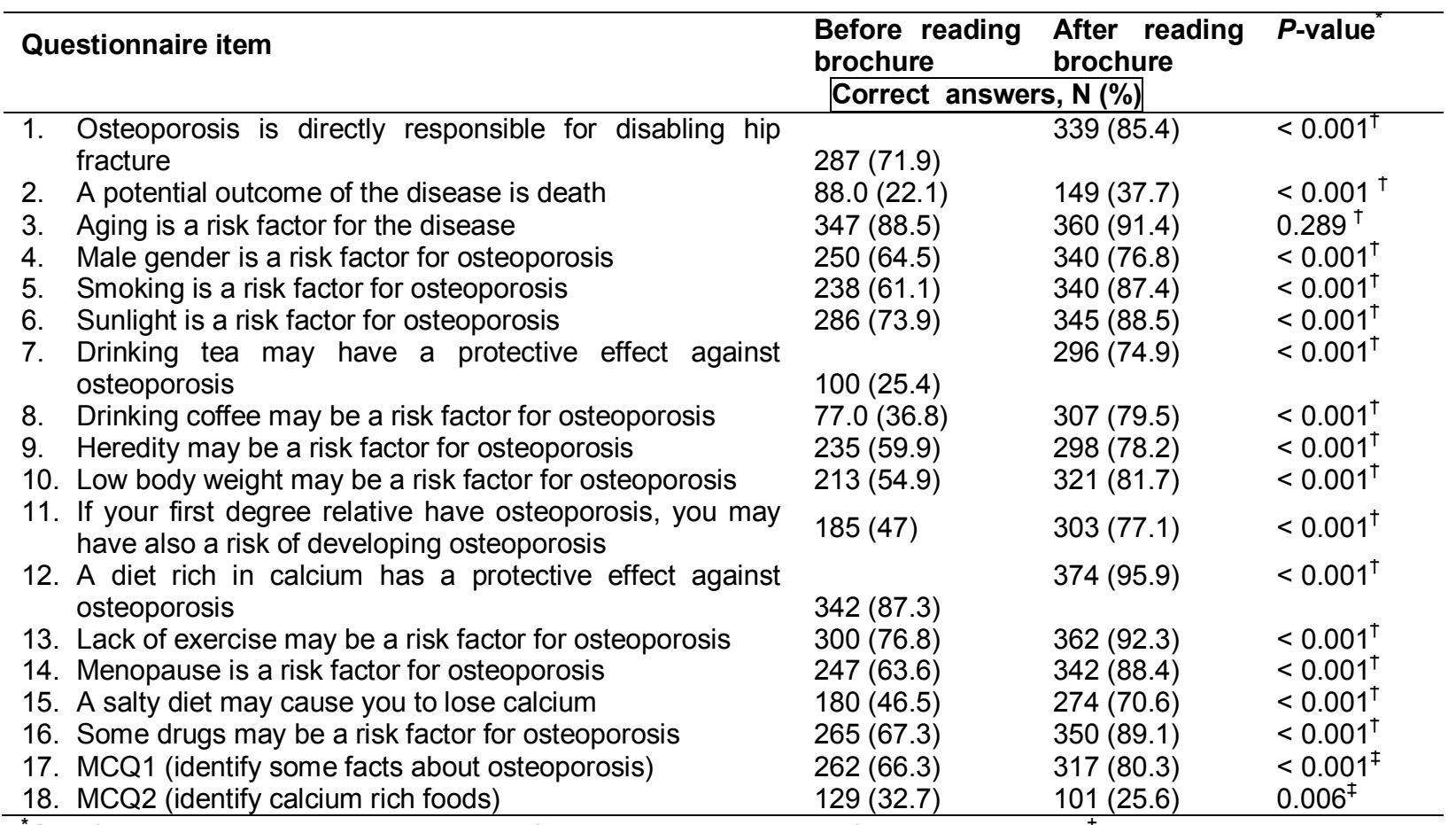

"Significant at $\alpha=0.01$ to compensate for multiple analysis (Bonferroni correction); ${ }^{\dagger} p$-values were calculated using McNemar test; ${ }^{\ddagger} p$ values were calculated using Wilcoxon signed ranks test

\section{DISCUSSION}

In busy health systems such as that in Jordan [12], there is no enough time to provide adequate counseling about disease and medications. Therefore, targeted educational programs are needed to increase patients' knowledge regarding chronic conditions such as osteoporosis. This study has shown that a simple pharmacist-directed brochure provided to participants was successful in increasing their short-term knowledge, which can pave the way towards effective means of osteoporosis prevention and management.

To our knowledge, this is the first study that evaluates the knowledge of risk factors in both men and women in Jordan, and also the first study that includes men's knowledge of osteoporosis risk factors in the region. This important highlight arises from the fact that this group of patients is always neglected in similar studies $[4,5,9]$. 
The Jordanian Osteoporosis Prevention Society (JOPS) has previously undertaken two major osteoporosis studies. The first was a national osteoporosis record (FiJoNOR) survey, which involved a national sample of 821 females, aged 20-89. Results showed that $50.3 \%$ of the sample illustrated insufficient vitamin D levels (25-OHD level $<50 \mathrm{nmol} / \mathrm{L}$ ) and $33.3 \%$ were deficient in these levels $(25-\mathrm{OHD}$ level $<25 \mathrm{nmol} / \mathrm{L})$. The second follow-up major study was designed to determine the incidence of fragility (osteoporotic) hip fractures in Jordanians (FiJoHip). This study identified an estimate of 1008 hip fractures a number that is expected to quadruple by 2050 . About $80 \%$ of all hip fractures are surgically treated with direct hospital costs estimated around USD 7000 per operation, costing the community huge expenses [13].

So it is clear that educational programs for osteoporosis are currently needed in the Jordanian society. Such programs can provide increased understanding of people's knowledge and beliefs regarding the disease, and result in improved behaviors which can serve as the basis for primary and secondary prevention of shortand long-term complications.

The fact that osteoporosis is not just confined to one group of people adds a further dimension to the issue of prevention and management. In recent years, osteoporosis has been increasingly recognized in men [14]. Men over 50 years of age have a $13-25 \%$ lifetime risk of fracture of the hip, spine or distal forearm $[15,16]$. Approximately one-third of hip fractures occur in men and even have a higher mortality than in women [17]. Studies focusing on this group of people are therefore needed. Furthermore, it has been acknowledged that osteoporosis is first diagnosed following the occurrence of fractures or along another serious health problem, and most women and men are unaware of the risk factors [1].

Hence, strategies to prevent osteoporosis are warranted. Prevention of osteoporosis starts with making the individuals aware of the risk factors, i.e. education. Many studies used workshops and group discussions to improve people's knowledge of the disease. In this study we used a simpler, more feasible, educational method that also proved effective. This is the first study conducted in Jordan to show that the 'brochure' as a simple inexpensive educational strategy is a successful approach to improve knowledge about osteoporosis. This feasible educational method improved people's knowledge of the disease significantly (score improvement from 56 to $78 \%$ ). Ultimately, the results of this survey may provide an increased understanding of the current knowledge for this disease amongst the Jordanian population and could serve as the basis for primary and secondary prevention efforts directed at Jordanian men and women.

Results from this study agree with previous results from similar studies conducted in Jordan and worldwide $[7,8,18]$. Results from an osteoporosis intervention program administered to adolescents from the USA, showed that a significant gain in knowledge about building healthy bones were shown [7]. Locally, a study aimed at assessing the role of educational sessions in promoting knowledge about osteoporosis in adolescents' females in Irbid, the second biggest city in Jordan, showed a significant increase in the overall knowledge of participants [19].

What makes this current study unique is that all previous studies conducted in Jordan focused on knowledge assessment in adolescents, middleaged and postmenopausal women $[19,20]$. This study is the first to focus on adult young women who are in their twenties and thirties, a stage at which the disease can be effectively prevented, and in men, an area that has not been explored previously.

According to this study, currently, Jordanians have a decent knowledge regarding osteoporosis, especially females. However, more than $70 \%$ of Jordanians believe that they need more education about osteoporosis. The educational brochure significantly improved knowledge in various important aspects. For example, it enhanced people's awareness regarding the negative effects of smoking, coffee drinking, and low-body weight as risk factors for osteoporosis (more than $100 \%$ difference between pre-education and post-education KOS). It also modestly (50 - $100 \%$ ) increased peoples' recognition of the importance of physical activity, use of drugs, correct diet and sunlight exposure.

Like all other educational methods, the educational brochure had its own drawbacks. It did not improve people's knowledge regarding certain very important areas, such as the appreciation of taking calcium-rich food as a protective factor for osteoporosis. Hence, need for a comprehensive educational program which cover more areas of osteoporosis knowledge and do not only depend on written material is needed. Visual/audio education, which may enhance patients' knowledge to a greater degree, should be explored in this area. In addition, future studies looking at the extent of knowledge 
retention following the provision of such educational programs are needed.

The level of awareness about osteoporosis was not just low amongst the general population, but also amongst the health care practitioners (with the exceptions of rheumatologists, orthopedists, endocrinologists and some gynecologist) [12].

Therefore, future research in this area needs to target the health care professionals as well. Pharmacists for example are in a pivotal position to deliver education and counseling on osteoporosis for a large number of people visiting the community pharmacy on daily basis [21].

Community pharmacies in Jordan are the most accessible health care facility in the country. People buying supplements for the prevention of osteoporosis, such as calcium and vitamin D, would only see the pharmacist out of all other health care professionals. Hence, highlighting the role of the pharmacist in this area for patients and other health care professionals is essential.

\section{Limitations of the study}

This study did not assess the long-term retained enhancement of knowledge and how enhancement of knowledge may affect behavioral changes amongst participants.

\section{CONCLUSION}

Current knowledge of osteoporosis by Jordanians is modest, especially females. However, $>70 \%$ of Jordanians believes that they need more education about osteoporosis. The educational brochure significantly improved knowledge in various important aspects such as negative effects of smoking and coffee drinking, while it was neutral (or even negative) in other facets. Comprehensive educational programs which cover more areas of osteoporosis knowledge, and do not only depend on written material are therefore warranted.

\section{ACKNOWLEDGEMENT}

The research was supported by the Dean of Academic Research of the University of Jordan through the principal investigator of this project. The sponsor of the study had no role in data collection and analysis of data writing manuscript. The authors would like to thank all volunteers who took part in the study.

\section{REFERENCES}

1. Assessment of fracture risk and its application to screening for postmenopausal osteoporosis. Report of a WHO Study Group. World Health Organ Tech Rep Ser. 1994; 843:1-129. Available at http://www.who.int/chp/topics/Osteoporosis.pdf. Accessed May 27, 2014.

2. Burge $R$, Dawson-Hughes $B$, Solomon $D H$, Wong JB, King A, Tosteson A. Incidence and economic burden of osteoporosis-related fractures in the United States, 2005-2025. J Bone Miner Res 2007; 22: 465-475.

3. Haentjens $P$, Magaziner $J$, Colón-Emeric CS, Vanderschueren D, Milisen K, Velkeniers B, Boonen $S$, Meta-analysis: excess mortality after hip fracture among older women and men. Ann Intern Med 2010; 152: 380-390.

4. Shilbayeh S. Prevalence of osteoporosis and its reproductive risk factors among Jordanian women: a cross-sectional study. Osteoporos Int 2003, 14: 929940.

5. Al-Qutob R, Mawajdeh S, Khalil A, Schmidt A, Hannak A, Masri $B$. The magnitude of osteoporosis in middleaged women. Saudi Med J 2001; 22: 1109-1117.

6. Cindas $A$, Savas $S$. What do men who are at risk of osteoporosis know about osteoporosis in developing countries. Scand J Caring Sci 2004; 18: 188-192.

7. Brown S, Schoenly L. Test of an educational intervention for osteoporosis prevention with US adolescents. Orthop Nurs 2004; 23: 245-521.

8. Ziccardi S, Sedlak C, Doheny M. Knowledge and beliefs of osteoporosis in college nursing students. Orthop Nurs 2004; 23: 128-133.

9. Ungan M, Tümer M. Turkish women's knowledge of osteoporosis. Fam Pract 2001; 18(2): 199-203.

10. Geller S, Derman R. Knowledge, beliefs, and risk factors for osteoporosis among African-American and Hispanic women. J Nat Med Assoc 2001; 93(1): 1321.

11. Internet world stats, usage and population statistics [homepage on the Internet]. Available from: http://www.internetworldstats.com. Accessed 2014 April 12.

12. Otoom S, Batieha A, Hadidi H, Hasan M, Al-Saudi K. Evaluation of drug use in Jordan using WHO patient care and health facility indicators. East Mediterr Health J. 2002; 8(4-5): 544-549.

13. International osteoporosis foundation, Middle East and Africa audit, statistics. Available from: http:// www.iofbonehealth.org/middle-east-africa-audit. Accessed 2014 April 12

14. McCloskey E. Assessing fracture risk in patients with osteoporosis. Practitioner. 2013; 257(1765): 2,3,1921.

15. Bhattacharya RK, Vaishnav N, Dubinsky RM. Is there an increased risk of hip fracture in multiple sclerosis? Analysis of the Nationwide Inpatient Sample. J Multidiscip Health. 2014; 7: 119-122.

Trop J Pharm Res, December 2014; 13(12): 2107 
16. Bilezikian J. Osteoporosis in men. J Clin Endocrinol Metab 1999; 84: 3431-3434.

17. Sidlauskas KM, Sutton EE, Biddle MAOsteoporosis in men: epidemiology and treatment with denosumab. Clin Interv Aging. 2014; 9: 593-601.

18. Harvey C. Osteoporosis prevention teaching in our nation's schools: Options: how it works Orthop Nurs 2002; 21: 80-81.

19. Abushaikha L, Omran S, Barrouq L. Osteoporosis knowledge among female school students in Jordan. East Mediterr Health J 2009; 15(4): 906-911.
20. Amre H, Safadi R. Jordanian nursing students' knowledge of osteoporosis. Int J Nurs Practe 2008; 14: 228-236.

21. Qunaibi E, Basheti I, Hamadi S, Bulatova N, Shanah A, Abu-Gharbieh E. Effect of Divergence in Patients' Socioeconomic Background on their Perspective of the Role of the Community Pharmacist in Amman, Jordan. Trop J Pharm Res 2013; 12(2): 247-253. 